\title{
SITC.N
}

KONKURENTNOST

TURISTIČKE DESTINACIJE

TOURISM

DESTINATION COMPETITIVENESS

DOI: 10.15308/sitcon-2015-273-276

\section{ZNAČAJ OBRAZOVANJA LJUDSKIH RESURSA U HOTELIJERSTVU}

\author{
Mirjana Šekarić1, Marina Milovanović ${ }^{1}$, Marina Kostić2 ${ }^{2}$ Jelena Šekarić Sotirovski ${ }^{3}$ \\ ${ }^{1}$ Univerzitet Singidunum, Danijelova 32, Beograd, Srbija \\ ${ }^{2}$ Doo Montenegro Art, Budva, Crna Gora \\ ${ }^{3}$ Crédit Agricole a.d., Braće Ribnikar 4-6, Novi Sad, Srbija
}

\begin{abstract}
Apstrakt:
Turizam je jedna od najvažnijih uslužnih delatnosti, koja je u proteklih nekoliko decenija bitno uticala na ekonomski razvoj određenih zemalja i turističkih destinacija. Ljudski resursi predstavljaju vrlo važan sektor, ako ne i najvažniji u poslovanju svakog preduzeća u oblasti turizma. Cilj ovog rada jeste da predstavi značaj zaposlenih u hotelijerstvu u Srbiji, njihov stepen stručne spreme i zadovoljstvo radnim okruženjem i uslovima koje imaju kod poslodavca. Hipoteza postavljena u radu je da kadrovi u hotelijerstvu u Srbiji poseduju potrebne kvalifikacije, ali su vrlo često nezadovoljni uslovima rada. Ovaj rad ima za cilj da ukaže na mere koje bi top menadžment nekog turističkog preduzeća, odnosno hotela, mogao da primeni kako bi se povećalo zadovoljstvo i produktivnost zaposlenih.
\end{abstract}

\section{Ključne reči:}

hoteli,

ljudski resursi,

obrazovanje,

menadžment,

strani jezici.

\section{UVOD}

Turizam je privredna delatnost koja se može da posmatrati kao globalna pojava. Turizam se razlikuje od ostalih privrednih delatnosti u:

- heterogenosti njene strukture,

- visokog stepena elastičnosti tražnje turističkih usluga i neelastičnosti ponude,

- naglašen sezonski karakter poslovanja,

- specifičnosti u pogledu karaktera rada ove delatnosti (Unković \& Zečević, 2008, str. 46).

Turizam kao privrednu delatnost ne možemo posmatrati izolovano, zato što turizam predstavlja sinergiju različitih privrednih i neprivrednih aktivnosti sa ciljem zadovoljenja potreba domaćih i stranih turista. Za turizam su karakteristične sezonske oscilacije, a to znači da su ograničeni turistički tokovi u relativno kratkom periodu godine.

Funkcije turizma se dele na primarne ili ekonomske i sekundarne ili neekonomske funkcije. Kada se uzima u obzir značaj turizma, pre svega se misli na značaj ekonomskih funkcija. Putem turizma se ostvaruje tzv. nevidljivi izvoz, odnosno prihodi za neku zemlju od inostranog turizma u njoj i tzv. nevidljivi uvoz, tj. rashodi određene zemlje po osnovu potrošnje odnosno turističkog odliva u druge zemlje. Svakoj zemlji je u interesu da joj je nevidljivi izvoz veći od nevidljivog uvoza, te inostrani turizam ima značajnu ulogu u razvoju turizma svake zemlje, pa i Srbije (Čačić, 2011, str. 13). Ekonomski razvoj bitno utiče na turistička preduzeća, pa tako ona prerastaju iz nacionalnih u međunarodne multinacionalne koja posluju na svetskom tržištu pa se moraju prilagoditi zahtevima okruženja koristeći savremenu tehnologiju.
Turizam ima dve faze u svom razvoju (Čerović, 2011, str. 11):

1. faza fordizma, do 1990. godine, koju karakterišu strogo određena standardizacija i čvrsto "upakovana" putovanja, a turistička tražnja bila je zasnovana na konceptu relativno niskih cena.

2. faza post-fordizma, posle 1990. godine, kada turizam postaje konkurentan u oblasti turističke ponude i tražnje pa postaje fleksibilniji, individualno orjentisan, ekološki, a sami turisti postaju svesni kvaliteta pa su nezavisniji i fleksibilniji. Uticaj globalizacije je evidentan.

Internet revolucija s kraja XX veka i početka XXI veka, uticala je na razvoj individualnih i potpuno nezavisnih turista, koji putem računara biraju destinaciju, prevoz, rezervišu smeštaj, plaćaju određene usluge i odlučuju se na individualna kraća, a češća putovanja. Potreba turista je da se za što kraće vreme, obiđe više različitih turističkih atrakcija, te je sve to uticalo na razvoj tematskog turizma.

Sve se više nameće tvrdnja da uspeh savremenog turističkog preduzeća ne zavisi od njegovog kapitala već od obrazovanosti i znanja njegovih zaposlenih. Savremeno turističko preduzeće mora da ima sposobnost da se prilagodi uslovima na tržištu. Na tom tržištu moć poseduje onaj koji poseduje informaciju, u ovom slučaju moć ima "kupac" turističkih usluga. Savremeni menadžer u takvom preduzeću je nosilac novih ideja, inspirator za zaposlene a da njihove sposobnosti i kreativnosti i znanje posmatra kao vrlo cenjeni kapital koji će pretvoriti u prednost nad konkurencijom. Zaposleni koji poseduju znanje i stručnost zahtevaju da se usavršavaju u struci da se poštuje njihov status u preduzeću da bude motivisan i da imaju mogućnost napredovanja, a zadatak menadžera je da sačuva zaposlene od konkurencije i da tu- 
rističko preduzeće vodi odgovorno i da uspešno posluje na tržištu (Čačić, 2014, str. 216).

\section{METODOLOGIJA}

U radu su izloženi rezultati anonimne ankete sprovedene među zaposlenima u hotelijerstvu u januaru 2015. godine. Analizom i sintezom dobijenih rezultata, kao i korišćenjem statističkih podataka, biće prezentovane mere koje bi bile neophodne da se zadovoljstvo zaposlenih u hotelijerstvu poveća i da se menadžment aktivno uključi u obrazovanje i dodatno usavršavanje svojih kadrova.

\section{LJUDSKI RESURSI U HOTELIJERSTVU}

Ljudski resursi, kadrovi ili radna snaga, predstavljaju svakako najvažniji segment $\mathrm{u}$ funkcionisanju hotela i ugostiteljskih objekata. Ljudski resursi u hotelijerstvu definišu se kao humani kapital koji ima potencijalnu sposobnost da opremljen fizičkim kapitalom ostvari određenu proizvodnost rada i da na tržišstu u razmenu za radnu snagu ostvari dohodak, odnosno novu vrednost (Blagojević \& Redžić, 2009 , str. 253). Satisfakcija potrošača direktno je povezana sa zaposlenima u turizmu, bez obzira na stepen stručne spreme i poziciju na kojoj se nalaze. Od spremačice, preko kuvara, konobara, recepcionera do top menadžmenta, svi zaposleni imaju jednu i najvažniju misiju - zadovoljnog potrošača koji će se vratiti ponovo ili preporučiti hotel u kome je boravio. Iz tog razloga od izuzetnog značaja je proces pripreme i održavanja uslužnog programa hotelskog i restoranskog preduzeća i formiranje optimalnog sastava kolektiva (Čačić, 2014, str. 213).

Pored ovoga, otežavajuća okolnost kod formiranja kadrova u hotelijerstvu jeste sezonski karakter hotela na određenim destinacijama, usled čega dolazi do česte promene zaposlenih. U takvoj situaciji otežano je izvršiti i regrutaciju i selekciju kandidata za određeni posao. U sezoni, kada je potreba za ljudskim resursima u turizmu povećana, dolazi često i do zapošljavanja ljudi koji nemaju sve neophodne kvalifikacije za rad u hotelu (Vemić et al., 2010, str. 457). Suprotno tome, van sezone, veliki broj kako njih, tako i oni koji imaju sve neophodne kvalifikacije, ostaju bez posla, usled smanjenja obima posla.

Usled ovakvih promena u hotelima na određenim turističkim destinacijama, teško je zadržati, obrazovati i oformiti kadar.

O značaju razvoja hotelijerstva u Srbiji, kao i o značaju obrazovanja kadrova u hotelijerstvu, govore i statistički podaci Republičkog Zavoda za Statistiku Srbije o broju noćenja turista i o ostvarenom prometu:

Tabela 1. Dolasci i noćenja turista

\begin{tabular}{cccc}
\hline \multicolumn{4}{c}{ Republika Srbija } \\
\hline & Ukupno & Domaći & Strani \\
\hline 2009. & 6761715 & 5292613 & 1469102 \\
2010. & 6413515 & 4961359 & 1452156 \\
2011. & 6644738 & 5001684 & 1643054 \\
2012. & 6484702 & 4688485 & 1796217 \\
2013. & 6567460 & 4579067 & 1988393 \\
2014. & 6086275 & 3925221 & 2161054 \\
\hline
\end{tabular}

Izvor: Republički zavod za statistiku
Tabela 2. Godišnji promet u ugostiteljstvu u hiljadama RSD

\begin{tabular}{cccc}
\hline \multicolumn{4}{c}{ Republika Srbija } \\
\hline & Ukupno & Sever & Jug \\
\hline 2010. & 55002378 & 29808964 & 25193414 \\
2011. & 58219574 & 32367907 & 25851667 \\
2012. & 60841400 & 34384321 & 26457079 \\
2013. & 64685091 & 36656718 & 28028383 \\
\hline
\end{tabular}

Izvor: Republički zavod za statistiku

S obzirom da se turističko tržište jugoistočne Evrope smatra nedovoljno turistički istraženim i cela destinacija je sve interesantnija turistima iz celog sveta, zaključuje se da ozbiline mere u razvoju turizma, a samim tim i hotelijerstva, moraju biti preduzete, kako bi se poboljšao kvalitet usluge i kako bi se došlo do satisfakcije potrošača.

\section{OBRAZOVANJE LJUDSKIH RESURSA U TURIZMU}

Razvoj, obuka i obrazovanje, pre svega menadžerskih kadrova u turizmu od izuzetne je važnosti za održavanje konkurentske sposobnosti u turističkoj industriji. Turizam sam po sebi predstavlja područje koje karakteriše brz razvoj i primena inovativnih rešenja, te se očekuje da ljudski resursi u turizmu imaju i odgovarajuće formalno obrazovanje date struke, ali i da se konstantno stručno usavršavaju (Bakić, 2011, str. 31).

Turizam kao predmet i kao smer, pre svega se pojavio u okviru ekonomskih škola. Što se tiče visokoškolskih ustanova, turizam se izučavao na Ekonomskom fakultetu i na Prirodno-matematičkom fakultetu, u okviru Geografskog fakulteta. Savremeni turistički trendovi, značaj turizma i njegov uticaj na platni bilans zemlje, uticali su na potrebu da se turizam izdvoji i da se tretira kao zasebna delatnost. Ova pojava je uticala na povećanje broja srednjoškolskih i visokoškolskih ustanova koje se bave turizmom kao zasebnom uslužnom delatnošću.

Prema poslednjim podacima, privatne i državne srednje škole u Srbiji, u okviru kojih se izučava turizam su sledeće:

- Ugostiteljsko-turistička škola Beograd

- Srednja turistička škola Novi Beograd

- Ugostiteljsko-turistička škola sa domom učenika Vrnjačka Banja

- Ugostiteljsko-turistička škola Niš

- Ugostiteljsko-turistička škola Novi Pazar

- Ugostiteljsko-turistička škola Čajetina

- Srednja škola Svetozar Miletić Novi Sad

- Privatna srednja škola Sveti Arhangel, Kragujevac

- Privatna srednja škola Kosta Cukić, Beograd

- Privatna srednja škola "Dositej”, Beograd

- Prva privatna ugostiteljsko - turistička škola Beograd

- Elitna privatna ekonomska škola i gimnazija Novi Sad (Edukacija, 2015).

Kada su u pitanju visokoškolske ustanove, na sledećim ustanovama se izučava turizam:

- Departman za geografiju, turizam i hotelijerstvo, Prirodno-matematički fakultet, Novi Sad

- Fakultet za turistički i hotelijerski menadžment, Univerzitet Singidunum, Beograd 
- Fakultet za sport i turizam - TIMS, Univerzitet Educons, Novi Sad

- Ekonomski fakultet, studijski modul turizam i hotelijerstvo, Beograd

- Visoka poslovna škola strukovnih studija, studijski program turizam i hotelijerstvo, Novi Sad

- Geografski fakultet, katedra za turizmologiju, Beograd

- Poljoprivredni fakultet, studijski program agroturizam i ruralni razvoj, Novi Sad

- Visoka poslovno tehnička škola strukovnih studija, smer za turizam, Užice

- Visoka turistička škola strukovnih studija, Beograd

- Prirodno-matematički fakultet, master studijski program turizam, Niš

- Beogradska poslovna škola, studijski program menadžment turizma, Beograd (Turistički informator Srbije, 2015).

\section{REZULTATI I DISKUSIJA}

Neretko se u turizmu, a posebno u hotelijerstvu, kaže da su klijenti na drugom mestu, a zaposleni na prvom. Mnoge studije su pokazale da satisfakcija zaposlenih u hotelijerstvu direktno utiče na njihov odnos prema klijentu, te od toga u mnogome zavisi i uspešno poslovanje nekog preduzeća (Hayes \& Ninemeier, 2009, str. 23).

Januara 2015. godine sprovedena je anketa među zaposlenima u hotelskim preduzećima sa tri i četiri zvezdice u Beogradu. Od 61 ispitanika, 50,8\% muškaraca i 49,2\% žena, njih $57,4 \%$ je starosti od 35-45 godina.

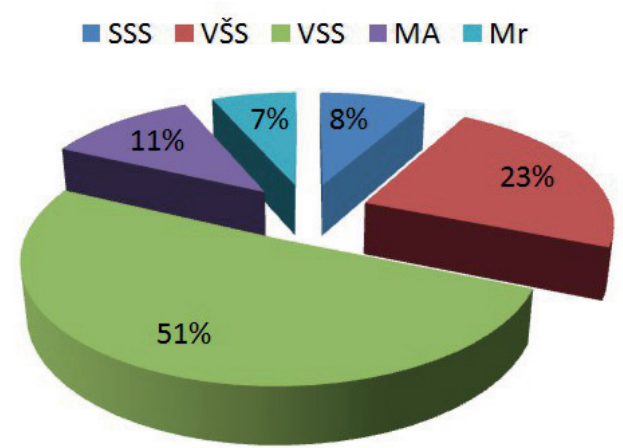

Slika 1. Stepen stručne spreme zaposlenih u hotelijerstvu (Sopstveni izvor)

Prema vrsti stručne spreme, $72,1 \%$ ispitanika ima obrazovanje koje je vezano za turizam.

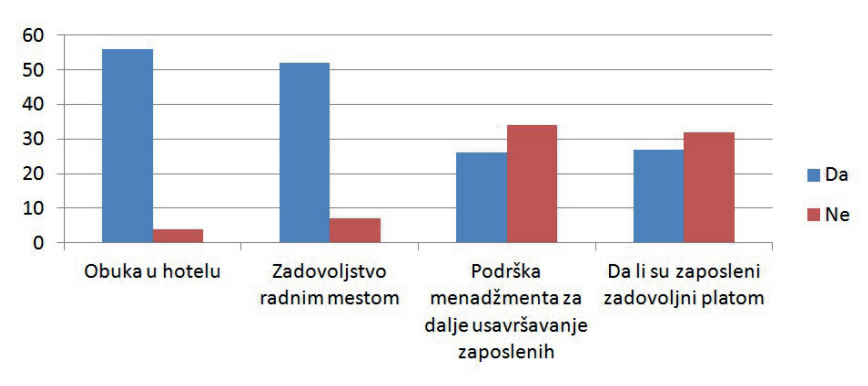

Slika 2. Odgovori ispitanika

(Sopstveni izvor)
Iako je značajan broj ispitanika imao obuku u hotelu i zadovoljan je radnim mestom, $56,7 \%$ ispitanika smatra da ih poslodavci ne motivišu niti im organizuju dodatne obuke, a 53,3\% ispitanika nije zadovoljno platom koju dobija na radnom mestu (Slika 2).

\section{ZAKLJUČAK}

Satisfakcija zaposlenih u turizmu zavisi od mnogih faktora. Prema sprovedenom istraživanju, preko polovine ispitanika nije zadovoljno platom koju dobija na određenom radnom mestu. Postavlja se pitanje - da li i koliko to njihovo nezadovoljstvo utiče na odnos sa klijentima i na opšte funkcionisanje hotelskog preduzeća?

U politici upravljanja ljudskim resursima, da bi se procenila efikasnost ljudskih resursa, predlaže se model $4 \mathrm{~K}$ (competence, commitment, congruence, cost effectiveness), odnosno kompetentnost, predanost, usklađenost između ciljeva kompanije i radnika i isplativost.

Uspostavljanje stimulativnih mera u vidu bonusa, komunikacija sa zaposlenim i uključivanje zaposlenih u dizajniranje i implementaciju rešenja predstavljaju neke od najvažnijih koraka u ostvarivanju zadovoljstva zaposlenih (Vlahović, 2008, str. 42).

Obuka i razvoj ljudskih resursa u hotelijerstvu jeste jedna od najvažnijih aktivnosti koju treba da sprovodi menadžment ljudskih resursa, ali se neretko ova aktivnost izostavlja. Razlog tome jesu česte promene zaposlenih u hotelijerstvu i sezonski karakter hotela na određenoj turističkoj destinaciji (Amirtharaj \& Cross, 2011, str. 44), te se organizovanje usavršavanja i obuka smatra neisplativom investicijom.

Prema Niksonu (Nickson, 2007, str. 16), ciklus koji bi trebao da ostvari menadžment ljudski resursa, kojim bi se povećala i satisfakcija i efikasnost zaposlenih u hotelskom preduzeću, trebao bi da izgleda ovako:

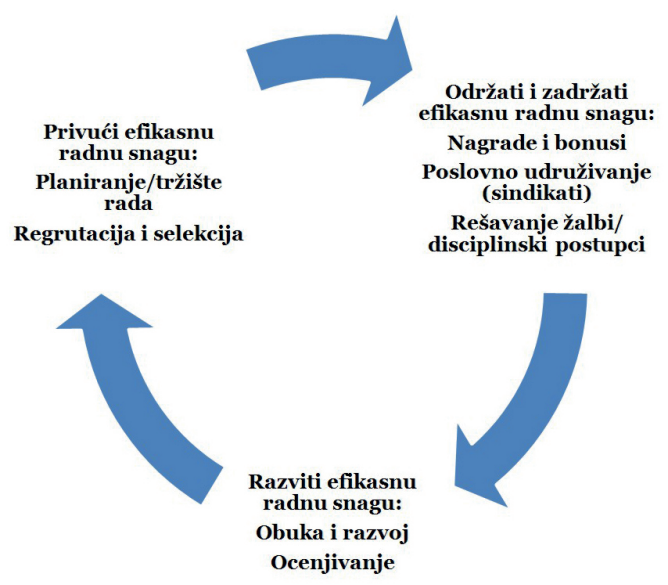

Slika 3. Menadžment ljudskih resursa Izvor: Nickson (2007, str. 16)

\section{LITERATURA}

Amirtharaj, D., \& Cross, K.R. (2011). HR concepts in hotel industry towards employee training and development. Internation Journal of Human Resources, 1(1), 44-56.

Bakić, O. (2011). Marketing u turizmu. Beograd: Univerzitet Singidunum. 
Blagojević, S., \& Redžić, V. (2009). Zaposlenost u hotelijerstvu u Republici Srbiji kao pokazatelj stanja ljudskih resursa u domaćem hotelijerstvu. Zbornik radova Departmana za geografiju, turizam i hotelijerstvo, 38/2009, 252-264. Novi Sad: Prirodno-matematički fakultet.

Čačić, K. (2014). Poslovanje hotelskih preduzeća. Beograd: Univerzitet Singidunum.

Čerović, S. (2011). Upravljanje ljudskim resursima u hotelijerstvu. Beograd: Univerzitet Singidunum.

Edukacija. (2015). Srednje škole u Srbiji. Preuzeto 15. marta 2015. sa http://srednjeskole.edukacija.rs/

Hayes, D.K., \& Ninemeier, J.D. (2009). Human Resources Management in the Hospitality Management. Hoboken: John Wiley \& Sons.

Nickson, D. (2007). Human Resource Management for the Hispitality and Tourism Industries. Oxford: Elsevier.

Republički zavod za statistiku. (2009-2014). Statistički godišnjak Republike Srbije. Preuzeto 3. maja 2015. sa http:// webrzs.stat.gov.rs/WebSite/
Turistički informator Srbije. (2015). Visokoškolske obrazovne institucije za turizam. Preuzeto 3. maja 2015. sa http:// tourism.in.rs/index.php?option=com_content $\& v i e w=$ article\&id $=52 \&$ Itemid $=55$

Unković, S., \& Zečević, B. (2008.) Ekonomika turizma. Beograd: Ekonomski fakultet.

Vemić Đuroković, J., \& Gajić, T. (2010). Kvalitet upravljanja ljudskim resursima kao ključni faktor uspešnosti turističke organizacije. Ekonomske teme, 3, 453-465.

Vlahović, S. (2008). Značaj kadrovske strukture za razvoj hotelske industrije Crne Gore. Hotelska kuća 2008: VII naučno stručni simpozijum - sa međunarodnim učešćem: Prilagođavanje Srbije i zemalja regiona očekivanim trendovima u hotelijerstvu Evrope i sveta. Beograd: Poslovno udruženje hotelsko ugostiteljske privrede-HORES.

\section{THE IMPORTANCE OF HUMAN RESOURCES EDUCATION AND TRAINING IN THE HOTEL INDUSTRY}

\footnotetext{
Abstract:

Tourism is one of the most important services sectors, which has had a considerable bearing on the overall economic development of certain countries and tourism destinations over the past few decades. Human resources sector is considered one of the key segments of any tourism enterprise. The principal aim of this paper is to highlight the importance of employees in the hotel industry in Serbia, their level of qualification and overall satisfaction with the work environment and conditions provided by the employer. The hypothesis presented in the paper is that human resources in the hotel industry in Serbia are well-qualified, but often quite unsatisfied with the current working conditions. The purpose of this paper is to indicate measures that the management of a tourist enterprise or a hotel could implement to enhance the overall employee satisfaction and maximize their productivity.
}

\begin{tabular}{l}
\hline Key words: \\
hotels, \\
human resources, \\
education, \\
management, \\
foreign languages.
\end{tabular}

